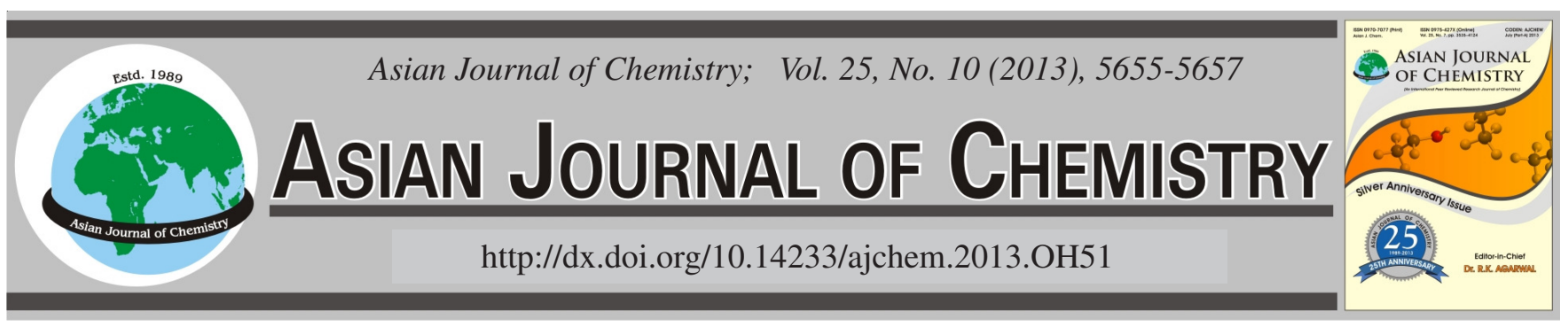

\title{
Crystal Structure and Properties of $\mathrm{Na}_{2} \mathrm{O}-$ Modified $\mathrm{K}_{0.47} \mathrm{Na}_{0.47} \mathrm{Li}_{0.06} \mathrm{Nb}_{0.96} \mathrm{Sb}_{0.04} \mathrm{O}_{3}-\mathrm{SrTiO}_{3}$ Piezoelectric Ceramics $\dagger$
}

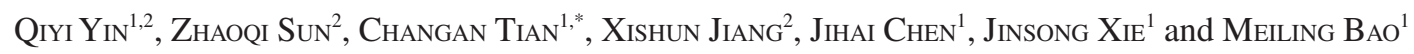

\begin{abstract}
${ }^{1}$ Department of Chemistry and Material Engineering, Hefei University, Hefei 230022, P.R. China
${ }^{2}$ School of Physics and Material Science, Anhui University, Hefei 230039, P.R. China

*Corresponding author:E-mail: tianchangan@hfuu.edu.cn
\end{abstract}

$\mathrm{Na}_{2} \mathrm{O}$-modified (1-x) $\mathrm{K}_{0.47} \mathrm{Na}_{0.47} \mathrm{Li}_{0.06} \mathrm{Nb}_{0.96} \mathrm{Sb}_{0.04} \mathrm{O}_{3}-\mathrm{xSrTiO}$ (abbreviated as KNLNS-ST, $\mathrm{x}=0,0.015,0.035,0.055,0.08$ ) Lead-free piezoelectric ceramics were fabricated by conventional ceramics sintering technique at $1050{ }^{\circ} \mathrm{C}$ and their crystal structure, dielectric and piezoelectric properties were systematically investigated. The X-ray diffraction revealed that all ceramics possessed a pure perovskite structure and a morphotropic phase boundary between the tetragonal and rhombohedral phases was identified in the composition range of $0.015 \leq \mathrm{x} \leq 0.035$, leading to a significant improvement in the electrical properties of the ceramics. The ceramic with $\mathrm{x}=0.035$ exhibited excellent properties at room temperature $\left(\mathrm{d}_{33}=186 \mathrm{pC} / \mathrm{N}, \mathrm{k}_{\mathrm{p}}=42 \%, \varepsilon_{\mathrm{r}}=1116, \tan \delta=1.8 \%\right)$ owning to the formation of morphotropic phase boundary. These results indicated that the ceramic is a promising candidate material for lead-free piezoelectric ceramics.

Key Words: Lead-free, Piezoelectric, Dielectric, Ceramics, Phase structure.

ᄂ - - - - - - - - - - - - - - - - - - - - - - - - - -

\section{INTRODUCTION}

With the strengthening to the view point of the sustainable development of the world, more and more people have paid extensive attention to environmentally friendly lead-free piezoelectric ceramics in recent years, especially, $\left(\mathrm{K}_{0.5} \mathrm{Na}_{0.5}\right) \mathrm{NbO}_{3}$ (KNN)-based ceramics, which mainly because their superior piezoelectric properties, high Curie temperature and environmental friendliness ${ }^{1-6}$. However, pure KNN ceramics are difficult to densifying by normal sintering due to the high volatility of alkaline elements at high sintering temperatures. Hence, a number of studies have been carried out to improve the sinter ability and electrical properties of the KNN ceramics, including the formation of new solid solutions of KNN with other ferroelectrics or nonferroelectrics, such as KNN-(Li, $\mathrm{Ag}) \mathrm{SbO}_{3}{ }^{5}, \mathrm{KNN}_{-} \mathrm{SrTiO}_{3}{ }^{6}$. Besides, there are a variety of sintering additives that reduce sintering temperature of the KNN ceramics, such as $\mathrm{CuO}^{7}$.

In this work, $\mathrm{Na}_{2} \mathrm{O}$-modified KNLNS-ST lead-free piezoelectric ceramics were fabricated and the effect of $\mathrm{Na}_{2} \mathrm{O}$ additives and $\mathrm{SrTiO}_{3}$ on electrical properties of the ceramics was also mainly studied. These results indicated that a enhanced piezoelectric and dielectric properties were obtained in the relatively low temperature sintering than previously reported ${ }^{8}$.

\section{EXPERIMENTAL}

The $\mathrm{Na}_{2} \mathrm{O}$-modified (1-x) $\mathrm{K}_{0.47} \mathrm{Na}_{0.47} \mathrm{Li}_{0.06} \mathrm{Nb}_{0.96} \mathrm{Sb}_{0.04} \mathrm{O}_{3}$ $\mathrm{xSrTiO}_{3}$ (abbreviated as KNLNS-ST, $\mathrm{x}=0,0.015,0.035$, $0.055,0.08$ ) lead-free piezoelectric ceramics were prepared by conventional solid-state sintering technique using excess $\mathrm{Na}_{2} \mathrm{O}$ additives. $\mathrm{K}_{2} \mathrm{CO}_{3}, \mathrm{Na}_{2} \mathrm{CO}_{3}, \mathrm{Li}_{2} \mathrm{CO}_{3}, \mathrm{SrCO}_{3}, \mathrm{Nb}_{2} \mathrm{O}_{5}, \mathrm{TiO}_{2}$ and $\mathrm{Sb}_{2} \mathrm{O}_{3}$ were used as starting raw materials. They were ball milled for $8 \mathrm{~h}$ with agate ball media and alcohol. After calcination at $860{ }^{\circ} \mathrm{C}$ for $2 \mathrm{~h}$, the calcined powders were milled again and pressed into disks of $1.2 \mathrm{~cm}$ in diameter and $1 \mathrm{~mm}$ in thickness under $20 \mathrm{MPa}$ using PVA as a binder. The disk samples were sintered at $1050{ }^{\circ} \mathrm{C}$ for $2 \mathrm{~h}$ in air. Silver paste was fired on both sides of the samples at $650^{\circ} \mathrm{C}$ for $15 \mathrm{~min}$ as the electrodes for the electrical measurements. The samples were poled in $80^{\circ} \mathrm{C}$ silicon oil bath by applying a DC electric field of $3-5 \mathrm{kV} / \mathrm{mm}$ for $35 \mathrm{~min}$. The electrical properties of all ceramics were measured more than a day later. X-ray diffraction characterization of the ceramics was performed by using $\mathrm{CuK}_{\alpha}$ radiation (Rigaku, Tokyo, Japan). The piezoelectric constant $\mathrm{d}_{33}$ was measured using a piezo- $\mathrm{d}_{33}$ meter (ZJ-3A, China). The electromechanical coupling factor $k_{p}$ was determined by the resonance method using an impedance analyzer (HP4294A). The dielectric constant and dissipation 
factor of the ceramics were examined with a LCR analyzer (TH2816).

\section{RESULTS AND DISCUSSION}

Fig. 1 showed X-ray diffraction patterns of the KNLNSST ceramics synthesized at $1050{ }^{\circ} \mathrm{C}$ for $2 \mathrm{~h}$. As shown in Fig. 1(a), all the ceramics possessed a pure perovskite structure and no secondary phase was observed, which suggested that the dopants were completely diffused into the $\left(\mathrm{K}_{0.5} \mathrm{Na}_{0.5}\right) \mathrm{NbO}_{3}$ lattices, with $\mathrm{Li}^{+}$and $\mathrm{Sr}^{2+}$ entering the $\left(\mathrm{Na}_{0.5} \mathrm{~K}_{0.5}\right)^{+}$sites, meanwhile $\mathrm{Sb}^{5+}$ and $\mathrm{Ti}^{4+}$ occupying the $\mathrm{Nb}^{5+}$ sites, to formed a homogeneous solid solution. From Fig. 1(b), the enlarged and simulated XRD patterns of the ceramics in the range of $2 \theta$ from $44.5^{\circ}$ to $47.0^{\circ}$ also showed that the ceramics with $\mathrm{x}<0.015$ possessed the tetragonal phase. As $\mathrm{x}$ increased, a rhombohedral phase appeared and increased continuously. At $x>0.035$, the ceramics possessed the rhombohedral phase. These characteristics suggested that a tetragonal-rhombohedral morphotropic phase boundary is formed in the ceramics with $0.015 \leq \mathrm{x} \leq$ 0.035 at room temperature. As a result, it was feasible that the KNLNS-ST ceramics were fabricated with a relatively low sintering temperature using excess $\mathrm{Na}_{2} \mathrm{O}$ additives.
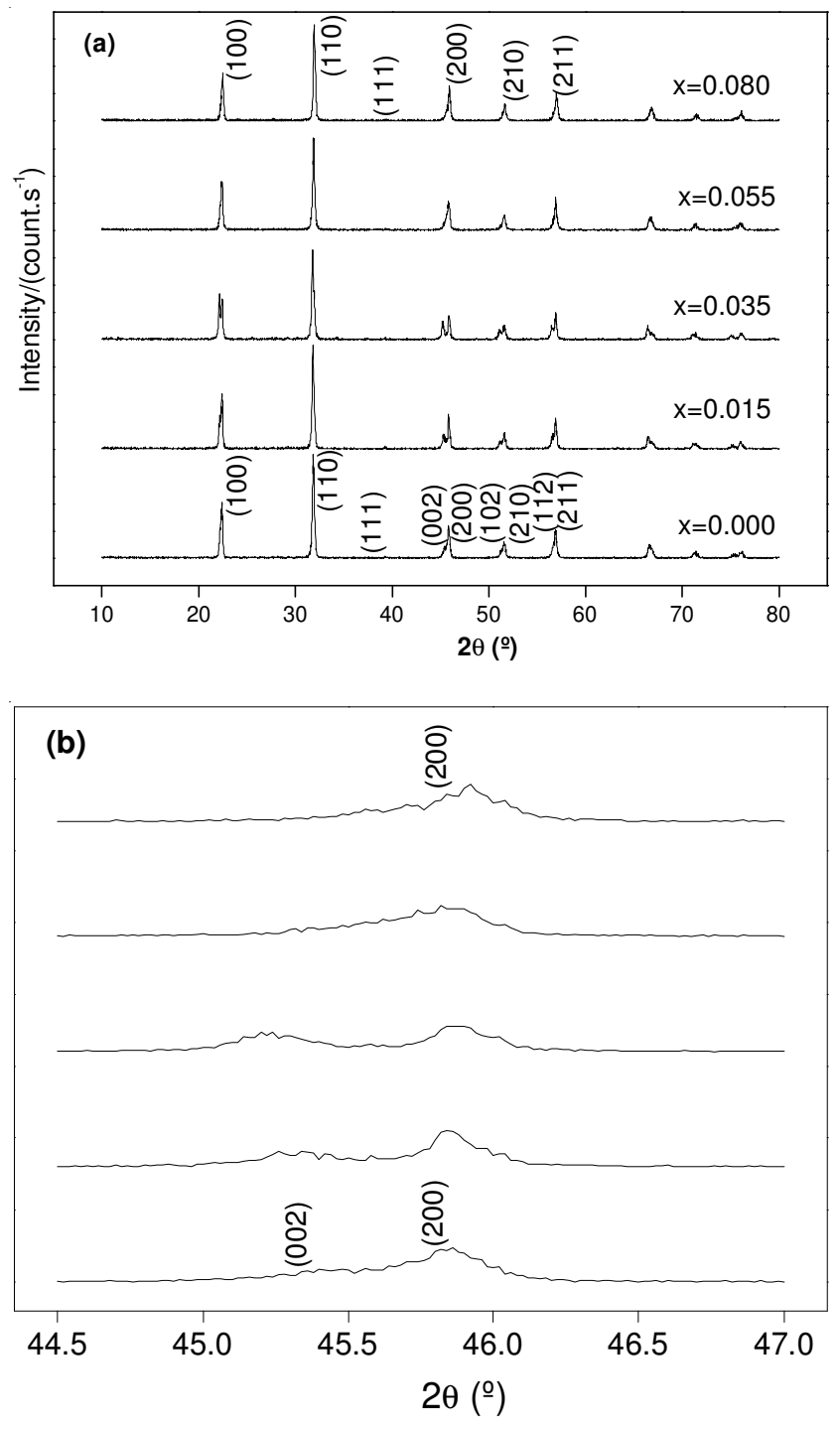

Fig. 1. (a) and (b) XRD patterns of the KNLNS-ST ceramics
Fig. 2 showed the $d_{33}, k_{p}, \varepsilon_{r}$ and tand of the KNLNS-ST ceramics as a function of $\mathrm{x}$. As shown in Fig. 2(a), the observed piezoelectric constant $\mathrm{d}_{33}$ increased sharply with increasing $\mathrm{x}$ and then decreased, giving a maximum value of $186 \mathrm{pC} / \mathrm{N}$ at $\mathrm{x}$ $=0.035$. Similar to $d_{33}$, the planar electromechanical coefficient $\mathrm{k}_{\mathrm{p}}$ also reached the maximum value of $42 \%$ at $\mathrm{x}=0.035$. It can be seen from Fig. 2(b), the observed $\varepsilon_{\mathrm{r}}$ and $\tan \delta$ showed similar dependences on $\mathrm{x}$ as well as $\mathrm{d}_{33}$, reching a maximum values $\left(\varepsilon_{\mathrm{r}}=1116\right.$ and $\tan \delta=1.8 \%$, respectively) at $\mathrm{x}=0.035$. As compared to other KNN-based ceramics, the KNLNS-ST ceramics exhibited optimum piezoelectric properties, which should be attributed to the increasing in the more possible polarization states resulting from the coexistence of the tetragonal and rhombohedral phases.
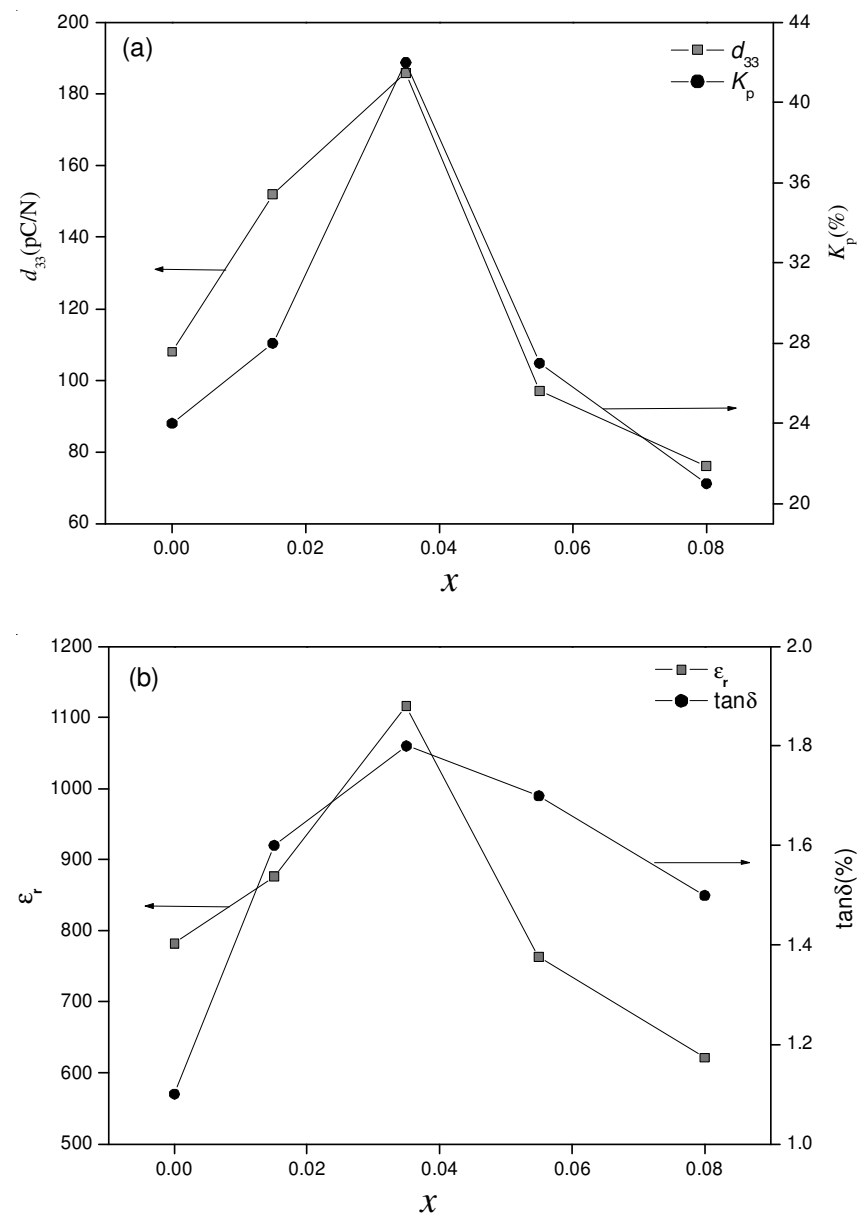

Fig. 2. (a) and (b). Piezoelectric and dielectric properties of the KNLNS$\mathrm{ST}$ ceramics as a function of $\mathrm{x}$

\section{Conclusion}

The $\mathrm{Na}_{2} \mathrm{O}$-modified (1-X) $\mathrm{K}_{0.47} \mathrm{Na}_{0.47} \mathrm{Li}_{0.06} \mathrm{Nb}_{0.96} \mathrm{Sb}_{0.04} \mathrm{O}_{3^{-}}$ $\mathrm{xSrTiO}_{3}$ lead-free piezoelectric ceramics have been fabricated by conventional solid state reaction technique. The effects of the amount of $\mathrm{SrTiO}_{3}$ and $\mathrm{Na}_{2} \mathrm{O}$ additives on the phase structure and electrical properties of $\mathrm{K}_{0.47} \mathrm{Na}_{0.47} \mathrm{Li}_{0.06} \mathrm{Nb}_{0.96} \mathrm{Sb}_{0.04} \mathrm{O}_{3}$ ceramics were systematically studied. XRD analysis of this system ceramics showed that a morphotropic phase boundary between tetragonal and rhombohedral phases was identified in the composition range of $0.015 \leq \mathrm{x} \leq 0.035$. The materials near the morphotropic phase boundary exhibited a strong compositional 
dependence and enhanced electrical properties. The ceramics of $\mathrm{x}=0.035$ showed optimum piezoelectric and dielectric properties at room temperature $\left(\mathrm{d}_{33}=186 \mathrm{pC} / \mathrm{N}, \mathrm{k}_{\mathrm{p}}=42 \%, \varepsilon_{\mathrm{r}}=\right.$ $1116, \tan \delta=1.8 \%)$. These results indicated that this system ceramics might be a potential candidate material for lead-free piezoelectric ceramics.

\section{ACKNOWLEDGEMENTS}

This work was supported by the National Nature Science Foundation of China (No. 51272001, 51072001, 51102073), the Natural Science Foundation of Anhui Province of China (No.10040606Q53, 1308085QB35), the Natural Science Foundation of Education Department of Anhui Province (No. KJ2013B229, KJ2012B154, KJ2010B148), the Laboratory of Environmental Material and Environmental Engineering of Jiangsu Province in China (No. K11031) and the College Students' Innovation and Entrepreneurship Training Program of China (No. 201211059005, 201211059006, 201211059007 , 201211059009, 201211059011), and the Teaching Research Projects of Hefei University (No.2012jyxm48).

\section{REFERENCES}

1. R.E. Jaeger and L. Egerton, J. Am. Ceram. Soc., 45, 209 (1962).

2. H. Birol, D. Damjanovic and N. Setter, J. Eur. Ceram. Soc., 26, 861 (2006).

3. Y. Saito, H. Takao, T. Tani, T. Nonoyama, K. Takatori, T. Homma, T. Nagaya and M. Nakamura, Nature, 432, 84 (2004).

4. K. Wang, J.F. Li and N. Liu, Appl. Phys. Lett., 93, 092904 (2008).

5. Y.Y. Wang, J.G. Wu, D.Q. Xiao, J.G. Zhu, P. Yu, L. Wu and X. Li, J. Alloys Comp., 462, 310 (2008).

6. R.C. Chang, S.Y. Chua, Y.P. Wong, C.S. Hong and H.H. Huang, J. Alloys Comp., 456, 308 (2008).

7. H. Takao, Y. Saito, Y. Aoki and K. Horibuchi, J. Am. Ceram. Soc., 89, 1951 (2006).

8. J.G. Hao, R.Q. Chua, Z.J. Xu, G.Z. Zang and G.R. Li, J. Alloys Comp., 479, 376 (2009). 